\title{
STUDY OF RUGGEDNESS HS-SPME PROCEDURE FOR ORGANOTIN ANALYSIS BY GC-PFPD
}

\author{
MANUEL BRAVO ${ }^{\prime *}$, GÄETANE LESPES ${ }^{2}$, WALDO QUIROZ ${ }^{\prime}$, IDA DE GREGORI ${ }^{1}$, HUGO PINOCHET , \\ AND MARTINE POTIN- GAUTIER ${ }^{2}$
}

\author{
${ }^{1}$ Laboratorio de Química Analítica y Ambiental, Instituto de Química, Pontificia Universidad Católica de Valparaiso, Avenida Brasil 2950, Valparaiso, Chile. \\ ${ }^{2}$ Laboratoire de Chimie Analytique, Bioinorganique et Environnement, UMR CNRS 5034 \\ Université de Pau et des Pays de L'Adour, Avenue de l'Université, 64014, Pau, France.
}

(Received: August 27, 2008 - Accepted: October 29, 2008)

\begin{abstract}
In this work, the ruggedness of several variables suspected influents on extraction of ethylated organotins (butyl-and phenyltins) by Solid Phase Microextraction in headspace mode (HS-SPME) was realized by using Gas Chromatography-Pulsed Flame Photometric detection (GC-PFPD). The influence of eight factors on SPME procedure was analyzed using an 11-factor, 12-experiment Plackett-Burman design on the chromatographic area normalized to either Tripropyltin or Diheptyltin area. After the results, the extraction of OTC by HS-SPME could be considered as rather robust as the factor effects were generally not significant or small when both internal standards were used.
\end{abstract}

\section{INTRODUCTION}

The ecotoxicological risk of organotin compounds (OTC) in the environment have been well recognized for some decades ${ }^{1}$. Use of organotin compounds (OTC) as fungicides, insecticides, bactericides, wood preservatives and PVC stabilizers lead to their release in the environment and thus contamination by these chemical forms. In terrestrial and aquatic media particularly, the OTC are present in sewage sludge, water, sediment, foodstuff and soil2. The major environmental problems have been reported for tributyltin (TBT), triphenyltyn $(\mathrm{TPhT})$ and their degradation products, di- and mono-substituted ${ }^{1}$.

As the toxicity of OTC depends on the nature and number of organic groups bonded to the tin atom, many analytical procedures have been developed for their determination in different environmental samples ${ }^{3,4}$. Species selective analysis of organotins is performed by coupled techniques based on the combination of a chromatographic separation with sensitive and selective detection method. The preferred separation technique for organotin compounds is gas chromatography (GC) due to its high resolution and detector versatility. In recent years, several detection methods for OTCs determination have been used, such as inductively coupled plasma mass spectrometry (ICP-MS) ${ }^{5}$ and pulsed flame photometric detection (PFPD) ${ }^{6}$. Recently, analytical performance of these detectors has been compared ${ }^{7}$. The cheapest PFPD was proposed for OTC determination in environmental samples.

The PFPD system has been applied in our laboratory to quantify organotins compounds in water, sediment, soil, sewage sludge and plant samples and showed a good performance. Unfortunately, some matrix effects have been found when analyzing samples with high carbon and sulfur content ${ }^{8,9}$. A decrease in sulfur interferences may be achieved applying some desulphurization procedures ${ }^{10}$ or adjusting PFPD parameters ${ }^{11}$. Recently, a reliable analytical method for organotin analysis by Headspace Solid Phase Micro-Extraction (HS-SPME) has been proposed improving the lack of selectivity of PFPD ${ }^{12}$. Herein, this procedure was validated by certified reference material analysis and the application of two internal standards improving the repeatability of simultaneous analysis of butyl- and phenyltins.

As is well known most speciation analysis methods are based on a succession of discrete steps $\mathrm{s}^{13,14}$ which may all be prone to systematic errors. The actual calibration strategies are based on the application of internal standards and/or standard additions to mitigate matrix effects and improve repeatability. However, this assumption must be demonstrated evaluating the influence of each variable and the experimental ranges considered in the procedure on the analytical response. Several approaches must be considered, but ruggedness appears as most adequate.

Ruggedness evaluation has been required from IUPAC as a method performance characteristic ${ }^{15}$. It corresponds to resistance to change in the results produced by an analytical method when minor deviations are made from the experimental conditions. In order to verify method ruggedness, experimental design such as Packlett-Burman or supersatured approaches were reported ${ }^{16}$. Despite that this parameter has been widely evaluated in development of pharmaceutical methodologies, in the case of organotin speciation analysis has been scarcely studied.

In the present work, an experimental approach for selection of adequate internal standard for OTC determinations by HS-SPME is discussed. Attention was centered on the capacity for compensate the variability of eight experimental factors by ruggedness evaluation of HS-SPME methodology for simultaneous determinations of butyl- and phenyltins using a Plackett-Burman design.

\section{EXPERIMENTAL}

\section{Apparatus}

For the analysis of organotin compounds a Varian 3800 gas chromatograph (Walnut Creek, CA, USA) equipped with a PFPD system and a Varian 1079 split/splitless injector were used and a capillary column DB-1 $(30 \mathrm{~m} \times 0.25$ mm I.D.; Quadrex, New Heaven, CT, USA). Nitrogen was used as carrier gas (flow: $2 \mathrm{ml} \mathrm{min}^{-1}$ ). The chromatographic separation and detection parameters have been previously optimized and are precisely described elsewhere ${ }^{17}$. A high transmission band filter (320-540 nm; BG 12, Schott, France) was used to observe the emission corresponding to the $\mathrm{Sn}-\mathrm{C}$ emission with a gate delay of $4.0 \mathrm{~ms}$ and a gate width of $2.0 \mathrm{~ms}$.

The manual SPME device was obtained from Supelco. The coated phase selected for this study was polydimethyl-siloxane (PDMS, $100 \mu \mathrm{m})$.

A mechanical table with elliptic stirring KS 2502 basic (Prolabo, Fontenay Sous Bois, France) was used for the derivatization/extraction step.

\section{Reagents and materials}

High quality water (18M $\Omega$ ) obtained from a Milli-pore system was used to prepare all solutions (Milipore, Bedford, MA, USA). The organotin standards such as dibutyltin dichloride, tributyltin chloride, diheptyltin chloride and trioctyltin chloride were obtained from Sigma-Aldrich (St. Quentin Fallavier, France). Tripropyltin chloride, monobutyltin trichloride, monophenyltin trichloride, diphenyltin dichloride, triphenyltin chloride were purchased from Strem Chemicals and monooctyltin trichloride, dioctyltin dichloride from Lancaster (Strasbourg, France). Stock solutions of these reagents (1000 mg $\mathrm{I}^{-1}$ as tin) were prepared in methanol and stored at $+4^{\circ} \mathrm{C}$ in the dark. Standard working solutions were made weekly and daily.

Sodium acetate, isooctane, nitric and acetic acids were purchased from J. T. Baker (Baker analyzed). Sodium tetraethylborate $\left(\mathrm{NaBEt}_{4}\right)$ was obtained from Galab products (Geesthacht, Germany).

\section{Derivatization and HS-SPME procedure.}

The ethylation conditions have been optimized previously $1^{4}$. Briefly, 0.1 $\mathrm{mL}$ of a standard mixture of butyl- and phenyltin (10 $\left.\mathrm{ng} \mathrm{Sn}^{-1}\right)$ prepared in acetic acid was introduced directly into the derivatisation vessel, total volume $100 \mathrm{~mL}$, containing $60 \mathrm{~mL}$ buffer solution. After addition of $50 \mu \mathrm{L}$ ethylating solution the mixture was mechanically stirred. The fibre was then placed in the headspace volume and the mixture was stirred again. The fibre was then introduced directly into the GC-PFPD for thermal desorption of the analytes at $275^{\circ} \mathrm{C}$, in splitless mode for $3 \mathrm{~min}$. No memory effect on the fiber was detected. 


\section{Ruggedness Evaluation}

The ruggedness of a method is tested by deliberately introducing smal changes to the procedure and examining the effect on the results. The parameters and their levels considered in this study are presented in Table 1. The levels considered are not minor, but they were considered in order to demonstrate the effectiveness of each internal standard, due to similar chemical properties, for determination of volatiles and semi-volatile compounds in extreme conditions.

Table 1.- The factors and their levels considered for this ruggedness study.

\begin{tabular}{lccc}
\hline \multicolumn{1}{c}{ Factors } & Coded factors & \multicolumn{2}{c}{ Levels } \\
\cline { 3 - 4 } & & $(-1)$ & $(+1)$ \\
\hline pH ethylation & $\mathrm{A}$ & 4.71 & 4.84 \\
Extraction time (min) & $\mathrm{B}$ & 25 & 35 \\
Equilibrium time (min) & $\mathrm{C}$ & 10 & 14 \\
Desorption time & $\mathrm{D}$ & 3 & 5 \\
Buffer Volume $(\mathrm{mL})$ & $\mathrm{E}$ & 50 & 60 \\
Ethylating Volume $(\mu \mathrm{L})$ & $\mathrm{F}$ & 50 & 100 \\
Stirring rate (rpm) & $\mathrm{G}$ & 380 & 420 \\
Fiber Age & $\mathrm{H}$ & New & Used* \\
\hline
\end{tabular}

*After 50 injections

The effects of these factors were evaluated using a Plackett-Burman design for the variables presented in Table 2 and were normalized to the average nominal response for each $\mathrm{OTC}^{18}$. Eight experimental and three dummies variables were studied in twelve experiences. The dummies effects were used to evaluate the statistical significance of effects in accordance with previous work ${ }^{17,20,19}$. The experimental response considered in this study is the chromatographic area ratio between each analyte and TPrT and DHepT as I.S.

Table 2. The 11-factor 12 experiences Plackett-Burman design used to screen eight factors in the ruggedness study.

\begin{tabular}{cccccccccccc} 
& \multicolumn{11}{c}{ Factors } \\
\hline $\begin{array}{c}\text { Experi- } \\
\text { ment }\end{array}$ & $\mathrm{A}$ & $\mathrm{d}_{1}{ }^{*}$ & $\mathrm{~B}$ & $\mathrm{C}$ & $\mathrm{d}_{2}{ }^{*}$ & $\mathrm{D}$ & $\mathrm{E}$ & $\mathrm{F}$ & $\mathrm{d}_{3}^{*}$ & $\mathrm{G}$ & $\mathrm{H}$ \\
\hline 1 & 1 & 1 & 1 & -1 & 1 & 1 & -1 & 1 & -1 & -1 & -1 \\
2 & 1 & 1 & -1 & 1 & -1 & -1 & -1 & 1 & 1 & 1 & -1 \\
3 & 1 & -1 & 1 & 1 & -1 & 1 & -1 & -1 & -1 & 1 & 1 \\
4 & 1 & -1 & -1 & -1 & 1 & 1 & 1 & -1 & 1 & 1 & -1 \\
5 & 1 & -1 & 1 & -1 & -1 & -1 & 1 & 1 & 1 & -1 & 1 \\
6 & -1 & 1 & 1 & 1 & -1 & 1 & 1 & -1 & 1 & -1 & -1 \\
7 & -1 & 1 & -1 & -1 & -1 & 1 & 1 & 1 & -1 & 1 & 1 \\
8 & -1 & -1 & -1 & 1 & 1 & 1 & -1 & 1 & 1 & -1 & 1 \\
9 & -1 & -1 & 1 & 1 & 1 & -1 & 1 & 1 & -1 & 1 & -1 \\
10 & -1 & 1 & 1 & -1 & 1 & -1 & -1 & -1 & 1 & 1 & 1 \\
11 & 1 & 1 & -1 & 1 & 1 & -1 & 1 & -1 & -1 & -1 & 1 \\
12 & 1 & -1 & -1 & -1 & -1 & -1 & -1 & -1 & -1 & -1 & -1 \\
\hline
\end{tabular}

*: Dummies variables, used to estimate the standard error of each effect in according with ${ }^{19}$.

\section{RESULTS AND DISCUSSION}

Selection of internal standard

In order to improve the repeatability of OTC analysis by GC-PFPD, the application of an internal standard has been considered for liquidliquid extraction (LLE) ${ }^{17,18}$. However, in order to obtain reliable results for simultaneous determination of volatile and semi-volatile organotins the application of at least two internal standards for SPME in headspace mode appears as mandatory ${ }^{12}$. In this study, Tripropyltin (TPrT) and Diheptyltin (DHepT) were used as internal standards for volatile (Monobutyltin-MBT, Dibutyltin-DBT, TBT and Monophenyltin-MPhT) and semi-volatiles compounds (Diphenytin-DPhT and TPhT), respectively. It can be observed in Table 3 that an important improvement on repeatability evaluation is achieved by using both internal standards.

Table 3. Repeatability expressed as \% RSD obtained applying two internal standards for analysis of butyl- and phenyltins by HS-SPME ( $\mathrm{n}=10)$.

\begin{tabular}{ccccccc}
\hline \multirow{2}{*}{$\begin{array}{l}\text { Internal } \\
\text { standar }\end{array}$} & \multicolumn{5}{c}{ Relative Standar Deviation (\% RSD) } \\
\cline { 2 - 7 } & MBT & DBT & MPhT & TBT & DPhT & TPhT \\
\hline Tripropyltin & 2 & 8 & 10 & 5 & 24 & 9 \\
Diheptyltin & 15 & 18 & 23 & 20 & 9 & 8 \\
\hline
\end{tabular}

We strongly believe that the improvement obtained was probably due to differences in sorption behavior from the gas phase in headspace mode for each compound. In order to demonstrate this hypothesis, the sorption profiles of butyl- and phenyltins were obtained and are showed in Figure 1. As expected, two different kind of profile are found: volatile (Figure 1-A) and semivolatile compounds (Figure 1-B). Besides, as we can see in the sorption profile of TPrT (Figure 1-C) is very similar to MBT, DBT, TBT and MPhT, classified as volatiles. Thus, DHepT shows a profile comparable to DPhT and TPhT, classified as semi-volatile.

These results demonstrate that the semi-volitale compounds do not reach the equilibrium gas-solution in the experimental conditions established and a little variation in extraction time will increase the experimental error. However, DHepT shows the same extraction behavior and its application will allow us compensate the effect of extraction time on repeatability of chromatographic response for quantitative analysis.

In general, this aspect shall be considered to select one or several I.S. for simultaneous analysis of organotin compounds by SPME in headspace mode.
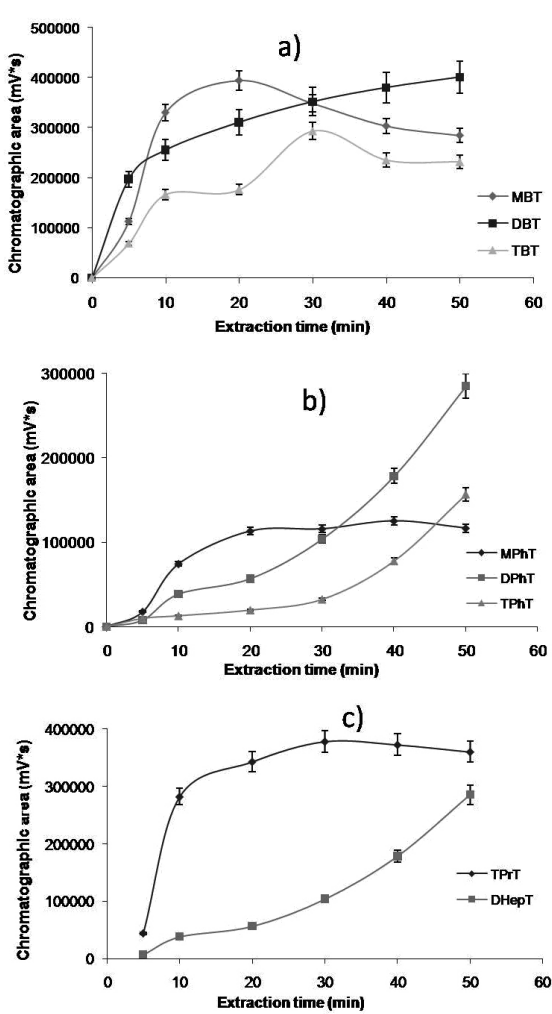

Figure 1.- Extraction profiles obtained by HS-SPME of ethylated a) Butyltins, b) Penyltins and c) tripropyltin (TPrT) and diheptyltin (DHepT). Abreviations: MBT (monobutyltin), DBT (dibutyltin), TBT (tributyltin), MPhT (monophenyltin), DPhT (diphenyltin) and TPhT (triphenyltin). 
Ruggedness

The effects of factors selected in this study and their critical values evaluated on chromatographic areas of organotin compounds, using two internal standards: TPrT and DHepT, are presented in Table 1. In literature, several error estimates have been reported to statistical interpretation of effects, but the use of dummy factor effects from Placket-Burman designs was found appropriate in ruggedness test ${ }^{16,19}$. Besides, the dummy effects are an estimation of experimental error for each response (see Table 2).

The calculated and the critical effects obtained by each OTC analyzed by HS-SPME-GC-PFPD are shown in Table 4. As expected, non significant effects of factors are observed for volatile compounds MBT, DBT and TBT when TPrT is used as internal standard. However, for MPhT, desorption time (positive effect) and buffer volume (negative effect) are significant. The phenyl group in ethylated MPhT probably produces more stable non-polar interactions than butyl substituents with SPME coating, requiring a higher desorption time. Besides, for MPhT, the analytical signal decrease when solution volume increases, indicating an effect over the distribution between gas-liquid phases of this analyte.

Table 4. Calculated effects (\%) of the factors on the SPME extraction of organotin in headspace mode using two internal standard.

\begin{tabular}{ccccccccccccc} 
& \multicolumn{3}{c}{ MBT } & \multicolumn{2}{c}{ DBT } & \multicolumn{2}{c}{ TBT } & \multicolumn{2}{c}{ MPhT } & \multicolumn{2}{c}{ DPhT } & \multicolumn{2}{c}{ TPhT } \\
\hline Effects & IS1 & IS2 & IS1 & IS2 & IS1 & IS2 & IS1 & IS2 & IS1 & IS2 & IS1 & IS2 \\
\hline A & -8.7 & $-15.3^{*}$ & -6.4 & $-25.9^{*}$ & 0.3 & $-19.2^{*}$ & -8.2 & $-24.8^{*}$ & -2.9 & -13.7 & 14.7 & -5.8 \\
B & -11.4 & $-17.3^{*}$ & -3.5 & $-17.3^{*}$ & 3.3 & $-13.7^{*}$ & -0.1 & $-15.7^{*}$ & 3.3 & -2.4 & 20.6 & 5.8 \\
C & -4.1 & $-13.6^{*}$ & -1.9 & -1.9 & -4.1 & 1.6 & -0.3 & 0.5 & 1.3 & 4.1 & 16.2 & 10.9 \\
D & -14.3 & $-12.3^{*}$ & -8.2 & $-18.5^{*}$ & -4.8 & $-19.2^{*}$ & $18.9^{*}$ & $-18.1^{*}$ & 6.1 & -7.3 & -15.2 & -0.8 \\
E & -13.8 & $-15.3^{*}$ & 5.1 & 1.9 & 7.9 & -0.5 & $-21.9^{*}$ & 1.4 & 4.4 & -0.8 & 18.5 & -4.2 \\
F & -0.7 & $-16.7^{*}$ & 1.7 & -9.9 & -3.7 & -8.2 & 4.6 & -4.3 & -3.5 & -0.8 & -16.9 & -12.6 \\
G & 4.6 & $-15.3^{*}$ & -1.5 & -4.3 & -3.5 & -2.8 & -2.4 & -8.6 & -5.7 & 2.4 & -15.8 & 7.6 \\
H & -5.6 & $-17.0^{*}$ & -0.2 & 3.1 & -8.4 & 0.5 & -8.8 & -3.3 & $-21.7 *$ & -2.4 & -33.7 & 12.6 \\
\hline $\mathrm{E}_{\text {critical }} \mathrm{b}$ & 14.7 & 11.6 & 9.2 & 16.7 & 8.9 & 11.8 & 14.9 & 14.4 & 26.0 & 13.7 & 50.2 & 13.8 \\
\hline
\end{tabular}

${ }^{a}$ The effect calculated were normalized to the average nominal response of each organotin (Y) using $\% E_{X}=\frac{E_{X}}{\bar{Y}} \cdot 100$

${ }^{\mathrm{b}} \mathrm{E}_{\text {critical }}=\mathrm{t}_{\text {critical }} \mathrm{SE}_{\mathrm{e}}$, where $\mathrm{SE}_{\mathrm{e}}=\sqrt{\frac{\sum_{\text {dummy }}^{2}}{n_{\text {dumy }}}} ; \Sigma E_{\text {dummy }}^{2}$ and $\eta_{\text {dummy }}$ correspond to sum

of squared dummy effects and number of dummy factors (three in this study), respectively ${ }^{19}$.

For semivolatile compounds (DPhT and TPhT) non-significant factors were found with both internal standards. However, the critical effect calculated for these compounds is higher when TPrT is used; suggesting an elevated experimental error and non reliable information can be obtained when this compound is used as internal standard. When DHepT is used as I.S. the critical value obtained for DPhT and TPhT is similar to critical value for volatile compound, indicating an acceptable performance for this approach.

\section{CONCLUSION}

After these results, in order to obtain reproducible data the application of two internal standards for simultaneous analysis of butyl and phenyltins by SPME in headspace mode (HS-SPME) has to be considered. Besides, the ruggedness of a SPME procedure in headspace mode for OTC determination was evaluated. The Plackett-Burman design used for ruggedness testing yielded the conclusion that HS-SPME procedure could be considered as rather robust when an adequate internal standard is used for volatile and semivolatile OTC. However, this study showed that MPhT is more affected for desorption time and buffer volume, where the chromatographic signal increases when the injection time increase and buffer volume decrease.

\section{ACKNOWLDGEMENTS}

The authors acknowledge the Program ECOS-CONICYT (Scientific cooperation project between France and Chile, action C01E010) for financial support. M. Bravo thanks to Conicyt and the French Government for the fellowships conceded.

\section{REFERENCES}

1. K. Fent. Crit. Rev. Toxicol. 26, 1, (1996).

2. M. Hoch. Appl. Geochem. 16, 719, (2001).

3. J.L. Gomez-Ariza, E. morales, I. Giraldez, D. Sánchez-Rodas, A. Velasco. J. Chromatogr. A 938, 211, (2001).

4. M. Abalos, J.M. Bayona, R. Compañó, M. Granados, C. Leal, M.S. Prats. J. Chromatogr. A 788, 1, (1997).

5. M. Üveges, P. Rodriguez-Gonzalez, J.I. García Alonso, A. Sanz Medel, P. Fodor. Microchemical Journal 85, 115, (2007).

6. J.A. Jacobsen, F. Stuer-Lauridsen, G. Pritzl. Appl. Organomet. Chem. 11, 737, (1997).

7. S. Aguerre, G. Lespes, V Desauziers, M. Potin-Gautier. J. Anal. At. Spectrom. 16, 263, (2001).

8. A. Wasik, B. Radke, J. Bolałek, J. Namieśnik. Chemosphere 68, 1, (2007).

9. M. Bravo, G. Lespes, I. De Gregori, H. Pinochet, M. Potin-Gautier. J. Chromatogr. A 1046, 217, (2004).

10. P. Schubert, I. Fernandez-Escobar, E. Rosenberg, J.M. Bayona. J. Chromatogr. A 810, 245, (1998).

11. T. Zuliani, G. Lespes, R. Milačič, J. Ščančar, M. Potin-Gautier. J. Chromatogr. A 1188, 281, (2008).

12. M. Bravo, G. Lespes, I. De Gregori, H. Pinochet, M. Potin-Gautier. Anal. Bioanal. Chem. 383, 1082, (2005).

13. C. Dietz, J. Sanz, E. Sanz, R. Muñoz-Olivas, C. Cámara. J. Chromatogr. A 1153, 114, (2007).

14. F. Adams, S. Slaets. Trends Anal. Chem. 19, 80, (2000).

15. M. Thompson, S.L.R. Ellison, R. Wood. Pure Appl. Chem. 74, 835, (2002). 
16. B. Dejaegher, Y. Vander Heyden. J. Chromatogr. A 1158, 138, (2007).

17. C. Bancon-Montigny, G. Lespes, M. Potin-Gautier. J. Chromatogr. A 896, $149,(2000)$.
18. C. Perrin, H. Fabre, M. Maftouh, D. Luc Massart. Y.Vander Heyden. J. Chromatogr. A 1007, 165, (2003).

19. B. Dejaegher, M. Dumarey, X. Capron, M.S. Bloomfield, Y. Vander Heyden. Anal. Chim. Acta 595, 59, (2007). 